\title{
Integrating a parenting intervention into pediatric primary care: A qualitative pilot study of stakeholders' perspectives
}

Ana Baumann ( $\sim$ abaumann@gwbmail.wustl.edu )

Washington University in Saint Louis https://orcid.org/0000-0002-4523-0147

Meagan Pilar

Washington University in Saint Louis

Callie Walsh-Bailey

Washington University in Saint Louis

\section{Short report}

Keywords: evidence-based parent intervention, pediatric primary care, adaptation, CFIR

Posted Date: May 7th, 2020

DOI: https://doi.org/10.21203/rs.3.rs-26009/v1

License: (c) (1) This work is licensed under a Creative Commons Attribution 4.0 International License.

Read Full License 


\section{Abstract}

Background In the U.S., children as early as two years old are being diagnosed with depression and other mental health problems. Children with chronic diseases also struggle with mental health problems. Evidence-based parent interventions can support these families by improving parenting practices. Pediatric primary care practices are ideal settings to provide parent interventions, as they can have broader reach, decrease stigma and improve health and mental health outcomes. There is currently no clear guidance as to how to integrate these interventions.

Methods With the scientific premise that primary care settings can be a powerful place to reach families, this study examined barriers and facilitators of implementing an evidence-based parenting intervention within a primary care practice-based network.

Results Semi-structured interviews were conducted with 16 community pediatricians in a Midwestern Practice-Based Research Network. The interview guide was developed based on the Consolidated Framework for Implementation Research (CFIR), with a particular emphasis on intervention characteristics and the organization's inner setting. A codebook was developed using CFIR. Interview transcripts were coded by two independent raters (kappa $=0.93$ ). Data were analyzed using directed content analysis.

Conclusions Themes at the outer and inner setting were identified as determinants. Using theory and stakeholder input will help adapt the intervention as well as its strategies to implement parent interventions in primary care settings.

\section{Contributions To The Literature:}

This study identifies specific barriers and facilitators to implement evidence-based parent interventions in pediatric primary care settings, as described by the providers (i.e., pediatricians)

We used the Consolidated Framework for Implementation Research to guide our semi-structured interview to capture determinants at the outer and inner settings.

Using a theoretical approach to examine the context will help guide the adaptation of the intervention and its implementation strategies, allowing for scientific reproduction and evaluation of our work

\section{Background}

In the United States (U.S), 17\% of children aged 2-8 years old experience behavioral problems $(1,2)$, estimating a total annual cost of $\$ 247$ billion (3). Children's behavioral problems can have long-term consequences on their developmental process (4). Similarly, about $15-19 \%$ of children in the U.S. have a chronic illness (5), a physical or mental condition that requires frequent medical care as there is no cure (6). Mental and behavioral health problems are strongly associated with children with chronic illness, such as asthma $(7,8)$, and sickle cell disease (9). 
Data show that parenting practices can mediate child behavior (10). Evidence-based parent interventions (EBPIs) decrease child behavior problems, with 60-70\% improvement in behaviors sustained for one year (11). EBPIs also decrease maternal depression and promote parent financial growth (12). The question now is not whether EBPIs are effective, but rather how and where to implement these interventions (11, $13,14)$ to reach children who are suffering.

There has been a strong movement to integrate EBPIs into primary care $(15,16)$. More than $90 \%$ of children in the United States see a primary care physician each year, making primary care ideal for early intervention $(17,18)$ and a powerful strategy to address disparities in care $(18)$. Moreover, because pediatric primary care is the usual source of care for children, these settings are the best place to provide mental health support for families (19). EBPIs could become part of preventive services, with universal access for children (19) thus increasing patient access and decreasing stigma (20,21). However, there are few specific recommendations on how to implement EBPIs in pediatric offices $(20,22)$. With the scientific premise that primary care settings can be an impactful place to reach families, we examined the determinants of implementing EBPIs in a Practice-Based Research Network (PBRN) of community pediatricians.

\section{Conceptual Framework}

Our work was informed by the Consolidated Framework for Implementation Research (CFIR) (23), an overarching framework comprised of five domains: intervention characteristics, outer setting, inner setting, characteristics of individuals involved, and the process of implementation. The CFIR has been widely used to evaluate pre, post, and ongoing implementation processes (24). We aimed to (a) examine how EBPIs would fit in pediatric primary care settings; (b) assess providers' perceived importance of EBPIs and interest in implementing such interventions; (c) gather insights into barriers to implementation, and; (d) explore modifications needed for the intervention to be successful.

\section{Methods}

This study employed semi-structured, in-person interviews with pediatricians and pediatric nurses from a PBRN affiliated with a Midwestern University. The institutional review board at the university approved the study.

\section{Setting and Providers}

Participants were recruited from a PBRN of community pediatricians affiliated with a Midwestern University. The network was created to improve the health of children and adolescents in the community by identifying and addressing gaps in knowledge about prevention, diagnosis and management of pediatric diseases in primary care. Currently, the network comprises 80 pediatricians and six pediatric nurse practitioners from 36 practices in the metropolitan urban, suburban, and rural areas of a Midwestern region. It is estimated that this group of pediatricians provides care to about 150,000 
children, $59 \%$ of whom are white, and $32 \%$ African American, indicating that providers have experience with diverse populations.

\section{Sample}

We used a convenience sample of 16 pediatricians. The majority of practitioners identified as female $(\mathrm{n}=$ $12,75 \%)$, and had an average of 18 years ( $S D=9.7$; range $=1$ to 34 years) of experience in practice. Eleven providers $(68 \%)$ reported being part of a pediatric group practice, three were in a multi-specialty group practice, one was self-employed, and one was at a single-physician practice. On average, providers reported that $21 \%$ of their patients were covered by Medicaid/Medicare insurance (SD $=20 \%$; range $=5-$ $75 \%)$.

\section{Data Collection}

One study team member (MP) conducted semi-structured interviews with each participant, which averaged 25 minutes in duration. The interview guide was developed based on the CFIR (23), with a particular emphasis on intervention characteristics (i.e. characteristics of the EBPI) and the organization's inner setting. Participants were asked about the prevalence of behavioral disorders in their practice, the availability of resources for parents, and their preferences for implementing an EBPI in the pediatric primary care office.

\section{Data Analysis}

Each interview was audio-taped and transcribed verbatim. Two team members (MP, CWB) created codes using the CFIR constructs, developed the codebook and reviewed each transcript multiple times to increase familiarity with the data. Once the research team reached agreement regarding the codebook, two team members (MP, CWB) conducted dual independent review and coding of each transcript using NVivo, Version 12 (QSR International, Cambridge, MA). Because CFIR was used to shape the interview guide and the codebook, data were analyzed using directed content analysis (24) to guide the identification of variables and the development of initial codes (26). The reviewers reached a high overall agreement (kappa $=.93)$, thus a consensus approach was not needed to resolve discrepancies $(27)$.

\section{Results}

Researchers identified themes, which were organized according to the outer setting, inner setting, and intervention characteristics CFIR domains. Table 1 shows the frequency of codes within each domain. 
Table 1

Frequency of code by CFIR domain

\begin{tabular}{|lll|}
\hline CFIR domain & Total \# mentions & \# providers mentioned \\
\hline Outer setting & 71 & 16 \\
\hline Inner setting & 115 & 16 \\
\hline Intervention characteristics & 89 & 16 \\
\hline
\end{tabular}

\section{Outer Setting}

The outer setting domain has constructs that refer to factors outside of the organization. The patients' needs and resources (i.e., the extent to which patient's needs are known by the organization) was a salient theme. Providers reported the challenges with working families who would struggle to have time to attend EBPIs

"Basically, the barriers are... cultural and socioeconomic and just again a lot of people

have jobs, and it's hard... working full time and taking care of your family, carving out time to go to a class about something can be difficult" (Participant 6).

"I think unfortunately, parents don't always put enough weight into how they can help their kids through these tough things and um for a number of reasons because they're busy with other kids, because they have to work two jobs, because they're caring for another parent or a parent of theirs. A resource of time is such a limitation for so many families." (Participant 11)

Providers also described barriers surrounding the availability of and distance to providers:

"There's a lack of services... There's just not enough providers for the load of patients that need help... I mean, you can't get in. It takes 5-6 months to see someone sometimes... By that time, parents lose interest sometimes or they problem solve it themselves. You have to be exceptionally motivated and organized from a parent's standpoint to navigate all of the resources that parents have to access. And sometimes if you are in a lower socioeconomic status or if you're in a state where you're just trying to get food on the table for your family, the time it might take to access resources can be overwhelming." (Participant 10)

\section{Inner Setting}

Providers repeatedly expressed interest in offering a program to support parents, including offering office space during working hours or making it available on evenings/weekends

"We all see it as a huge issue with our families who cope with that. We'd be willing to kind of make moves or bends to accommodate them." (Participant 11) 
"I've been hoping to do something like this at some point in time from this office because we have a space that is easy to get to, could be open in the afternoon or evening hours, when families would be available. I really think it's a need that pediatricians can fill, but we're very busy people and can't really do it during the daylight hours. But if there are other folks like yourself or other social workers or folks who've had training in some of these techniques to teach parents, what I envision is... more after hours or evening kind of sessions... But our office could be available for that. We have that big room that you were sitting in. But we also have sort of our lunchroom that's in the back that could be set up for a group discussion."(Participant 15)

Physicians also explained that the pediatric primary care setting is a convenient location and a "safe space," where physicians are trusted sources of information.

"Our parents have developed a big trust in us as physicians... And, I think with that trust if we have someone in our practice, they would feel that it was a unified, it's not somebody else, dealing somewhere else, that there might be communication, there might be a safe place to, they might have more confidence in seeing someone in the practice" (Participant 2).

Despite the enthusiasm, EBPIs seemed to be of low relative priority, providers emphasized the limited resources available for parents both within the pediatric primary care setting as well as in the community as a whole. Though some primary care offices offered resources for parents, such as recommended reading materials or additional consultations, many providers described them as insufficient for addressing parents' concerns:

"There's not enough. I think they [existing resources] are very helpful, but there's just not enough. They are sometimes hard to plug the parents into...Sometimes the counselors or the psychologists, they're full, the waiting time is long, so it's not that easy... They're not as available as we need them to be" (Participant 7).

\section{Intervention characteristics}

Cost of the intervention was a major theme; however cost, along with other themes on social determinants of health are reported elsewhere (28). The other main theme identified was related to the intervention's adaptability. Although providers felt that an EBPIs are needed and would be welcomed by parents, they acknowledged the relative complexity of many EBPIs. Some suggested having fewer sessions, while others recommended decreasing the length of each session.

"I think that for some problems, just a one-time visit might be enough... Other times, the parents may welcome a more intensive repetitive program, if that makes sense. It depends on the problem, right? So it would be nice to have either one of those... But we know, let's say with anxiety, cognitive behavioral therapy takes many visits to teach them what to do, because they didn't get there overnight. It'll take a while to fix it." (Participant 16)

Providers focused on the strategies to deliver the interventions. To increase convenience, they suggested in-home visits or offering the program in a community-based setting. 
"Well, proximity is important. Location, location, location. The closer it is to people, the more likely they are to go... Whether that be a church, whether it be a community center, it would be allowing you to do this" (Participant 16).

Providers also emphasized the importance of thinking about who would deliver the EBPI. Psychologists, social workers, and peers (i.e., another parent) were suggested as viable options, but greater emphasis was placed on the interventionist's personality and approachability.

"I think if it's convenient and the person's helpful, I don't think you need a PhD to counsel a family through some behavioral problems" (Participant 14).

There were mixed ideas regarding the intervention's delivery format. Some providers suggested a group format to encourage feelings of support and camaraderie. Others recommended a one-on-one format to allay concerns about stigma and judgment.

"And people might have fears about strangers, if it's in a group setting for example, a parenting class with ten strangers. They may feel uncomfortable or they don't want to feel stupid. They don't want to look like they don't know how to take care of... their own child and they don't want to show up because it implies that ya know that they're not a good parent... So they might not want to come if it's in a group setting." (Participant 6)

"Well, I think one-on-one helps a lot, but I think also, a small group, I think also helps some parents to realize, 'okay, they're going through the same thing. It's not just me."' (Participant 7)

Providers recognized the need for this type of program as a treatment and as a preventative approach.

"I think that it's one of the most important things to do in life is to be a parent and the frustrating, challenging aspect of it is that no one gets training in it, right? I mean, we take time to teach people how to drive cars, we take time to teach people education at school. And you learn lots of facts and how to think and how to speak in front of a group and things like that. But you don't really learn how to be a parent and yet the impacts of it are huge... So I think it would be a great thing to try to find a way to support families and parents with all the complexity that they have to deal with... It would be really helpful to have better answers or better training for those families, ideally, ahead of time... So it's not just about intervening when there's a problem, although that can happen. It would be great to train people to know how to take care of their child, how to parent their child, I guess. You know how to take care of them, you know how to put their diaper on and stuff like that. It's more than that." (Participant 15)

\section{Discussion}

In this pilot study, we examined the determinants to implement an EBPI in pediatric primary care setting. Providers highly endorsed the need for this type of intervention and its importance for their patients. However, they also mentioned challenges. Themes at the outer setting level, such as external policies regarding food availability and housing, highlighted the importance of addressing patients' needs and 
resources. Regarding the inner setting, providers indicated low tension for change when adopting EBPIs because they highlighted the need for such service for their clients. However, they also mentioned the (lack of) availability of resources, and low readiness for change due to competing demands, particularly space. These factors are related to how we will adapt the intervention and its delivery. Their high motivation for the intervention (characteristics of individuals) show, however, that these providers could be key champions in informing the implementation process.

Designing and adapting EBPIs to enhance the fit to new contexts (29) will be key to our success, especially if we aim to reach the most vulnerable families (30). Taking time to adapt the intervention for the context, using theory and stakeholder input (31) will be important. There is little guidance in the literature on how to adapt interventions for different settings (32), particularly as it relates to addressing outer setting contexts (33). Using the CFIR to guide our assessment highlighted the determinants that need to be addressed to enhance the fit of the intervention with the practices' culture and compatibility.

\section{Conclusions}

This pilot study contributes to the literature of EBPIs by providing empirical, theoretical guidance on the determinants that need to be addressed to adapt these interventions to pediatric primary care settings. Using a well-established framework for evaluation allow us to use consistent terminology and ensure that we are grounded in theory during our implementation process (34).

\section{Declarations}

- Abbreviations:

- EBPI: evidence-based parent intervention

- CFIR: Consolidated Framework for Implementation Research

- FRAME: framework for reporting adaptations and modifications to evidence-based interventions

- Ethics approval and consent to participate: This study was approved by the Washington University Institutional Review Board \#201711138

- Consent for publication: Consent for publication was obtained from all individuals who participated in interviews.

- Availability of data and materials: The qualitative data generated and/or analyzed during the current study are not publicly available because of participant's expectation that their identity would be kept confidential. De-identified transcripts may be available from the corresponding author on reasonable request.

- Competing interests: The authors declare that they have no competing interests

- Funding: This study was funded by a pilot program from the Institute of Public Health Center for Dissemination and Implementation from Washington University in St. Louis. AB is also funded by P50 CA-19-006, 3U01HL13399403S1, and 5U24HL136790. Research reported in this publication was 
supported by the Washington University Institute of Clinical and Translational Sciences grant UL1TR002345 from the National Center for Advancing Translational Sciences (NCATS) of the National Institutes of Health $(\mathrm{NIH})$. The content is solely the responsibility of the authors and does not necessarily represent the official view of the $\mathrm{NIH}$.

- Authors' contributions: $A B$ conceived the research question. MP and $A B$ developed the interviewed guide. MP interviewed providers. MP and CWB analyzed data. AB, MP and CWB drafted and reviewed the manuscript. All authors read and approved the final manuscript.

- Acknowledgements: The authors would like to thank Jane Garbutt and Sherry Dodd for their guidance in recruiting participants. We thank the participants for their time and wisdom shared with us. Thank you to Dr. Ozge Sensoy-Bahar for her guidance in drafting the interview guide. We thank Cora-Ann McElwain for her invaluable support in this study.

\section{References}

1. Center for Disease Confrol and Prevention. Data and Statistics on Children's Mental Health [Internet]. 2019 Apr. Available from: https://www.cdc.gov/childrensmentalhealth/data.html

2. Ghandour RM, Sherman LJ, Vladutiu CJ, Ali MM, Lynch SE, Bitsko RH, et al. Prevalence and Treatment of Depression, Anxiety, and Conduct Problems in US Children. J Pediatr. 2019;206:256267.e3.

3. Centers for Disease Control and Prevention. Mental Health Surveillance Among Children - United States, 2005-2011 [Internet]. 2013. Available from: https://www.cdc.gov/mmwr/preview/mmwrhtml/su6202a1.htm

4. Dishion T, Forgatch M, Chamberlain P, Pelham WE. The Oregon Model of Behavior Family Therapy: From Intervention Design to Promoting Large-Scale System Change. Behav Ther. $2016 \mathrm{Nov}$ 1;47(6):812-37.

5. U.S. Department of Health and Human Services, Health Resources and Service Administration, Maternal and Child Health Bureu. The National Survey of Children with Special Health Care Needs 2005-2006: Welcome to the Chartbook Web site! [Internet]. 2008 p. Rockville, Maryland: US. Available from:

https://webarchive.library.unt.edu/eot2008/20080916005141/http:/mchb.hrsa.gov/cshcn05/

6. Ollendick T, Schroeder C, editors. Encyclopedia of Clinical Child and Pediatric Psychology I Thomas H. Ollendick | Springer. New York, NY, US: Springer, US; 2003.

7. Oh H, Stickley A, Singh F, Koyanagi A. Self-reported asthma diagnosis and mental health: Findings from the Collaborative Psychiatric Epidemiology Surveys. Psychiatry Res. 2019;271:721-5.

8. Shaheen M, Teklehaimanot S. 3538 Asthma and Depression in Children: the Role of Family Structure. J Clin Transl Sci. 2019;3(s1):119-119. 
9. Moodly KL, Mercer K, Glass M. An Integrative Review of the Prevalence of Depression among Pediatric Patients with Sickle Cell Disease: Social Work in Public Health: Vol 34, No 4. Soc Work Public Health. 2019;34:343-52.

10. Forgatch MS, DeGarmo DS. Parenting through change: an effective prevention program for single mothers. J Consult Clin Psychol. 1999;67(5):711-24.

11. Carr A. The evidence base for family therapy and systemic interventions for child-focused problems. J Fam Ther. 2014;36(2):107-57.

12. Bullard L, Wachlarowicz M, DeLeeuw J, Snyder J, Low S, Forgatch M, et al. Effects of the Oregon model of Parent Management Training (PMTO) on marital adjustment in new stepfamilies: A randomized trial. J Fam Psychol. 2010;24(4):485-96.

13. Forgatch MS, DeGarmo D. Extending and testing the social interaction learning model with divorce samples. In: Antisocial behavior in children and adolescents: A developmental analysis and model for intervention. Washington, DC, US: American Psychological Association; 2002. p. 235-56.

14. Russell BS, Guite JW, Homan KJ, Tepe RM, Williams SE. Complementary Parent Components for Pediatric Pain Families: Innovations in Treatment. Children. 2020;7(1):4.

15. Stancin T. Commentary: Integrated Pediatric Primary Care: Moving From Why to How. J Pediatr Psychol. 2016;41(10):1161-4.

16. Stancin T, Perrin EC. Psychologists and pediatricians: Opportunities for collaboration in primary care. Am Psychol. 2014;69(4):332-43.

17. Thomas CR, Holzer CE. The Continuing Shortage of Child and Adolescent Psychiatrists. J Am Acad Child Adolesc Psychiatry. 2006 Sep;45(9):1023-31.

18. Hodgkinson S, Godoy L, Beers LS, Lewin A. Improving Mental Health Access for Low-Income Children and Families in the Primary Care Setting. Pediatrics. 2017;139(1).

19. Perrin EC, Leslie LK, Boat T. Parenting as Primary Prevention. JAMA Pediatr. 2016 01;170(7):637-8.

20. Asarnow JR, Rozenman M, Wiblin J, Zeltzer L. Integrated Medical-Behavioral Care Compared With Usual Primary Care for Child and Adolescent Behavioral Health: A Meta-analysis. JAMA Pediatr. 2015;169(10):929-37.

21. Kolko DJ, Perrin E. The integration of behavioral health interventions in children's health care: services, science, and suggestions. J Clin Child Adolesc Psychol Off J Soc Clin Child Adolesc Psychol Am Psychol Assoc Div 53. 2014;43(2):216-28.

22. Elkin TD, Sarver DE, Wong Sarver N, Young J, Buttross S. Future Directions for the Implementation and Dissemination of Statewide Developmental-Behavioral Pediatric Integrated Health Care. J Clin Child Adolesc Psychol Off J Soc Clin Child Adolesc Psychol Am Psychol Assoc Div 53. 2017 Aug;46(4):619-30.

23. Damschroder LJ, Aron DC, Keith RE, Kirsh SR, Alexander JA, Lowery JC. Fostering implementation of health services research findings into practice: a consolidated framework for advancing implementation science. Implement Sci IS. 2009 Aug 7;4:50. 
24. Kirk MA, Kelley C, Yankey N, Birken SA, Abadie B, Damschroder L. A systematic review of the use of the Consolidated Framework for Implementation Research. Implement Sci. 2016;11(1):72.

25. Elo S, Kyngäs H. The qualitative content analysis process. J Adv Nurs. 2008;62(1):107-15.

26. Potter WJ, Levine-Donnerstein D. Rethinking validity and reliability in content analysis. J Appl Commun Res. 1999;27(3):258-84.

27. McHugh ML. Interrater reliability: the kappa statistic. Biochem Medica. 2012;22(3):276-82.

28. Baumann A, Walsh-Bailey C, Pilar M. The role of social determinants of health in the preimplementation of parenting interventions within a primary care practice-based network. under review;

29. Lyon AR, Koerner K. User-Centered Design for Psychosocial Intervention Development and Implementation. Clin Psychol Publ Div Clin Psychol Am Psychol Assoc. 2016 Jun;23(2):180-200.

30. Baumann AA, Cabassa LJ. Reframing implementation science to address inequities in healthcare delivery. BMC Health Serv Res. 2020;20(1):190.

31. $10.1002 /$ jcop. 22279

Miller CJ, Wiltsey-Stirman S, Baumann AA. Iterative Decision-making for Evaluation of Adaptations (IDEA): A decision tree for balancing adaptation, fidelity, and intervention impact. J Community Psychol [Internet]. [cited 2020 Feb 2];n/a(n/a). Available from:

https://onlinelibrary.wiley.com/doi/abs/10.1002/jcop.22279

32. 10.3389/fpubh.2018.00293/full

Smith JD, Berkel C, Rudo-Stern J, Montaño Z, St. George SM, Prado G, et al. The Family Check-Up 4 Health (FCU4Health): Applying Implementation Science Frameworks to the Process of Adapting an Evidence-Based Parenting Program for Prevention of Pediatric Obesity and Excess Weight Gain in Primary Care. Front Public Health [Internet]. 2018 [cited 2020 Mar 15];6. Available from:

https://www.frontiersin.org/articles/10.3389/fpubh.2018.00293/full

33. Bruns EJ, Parker EM, Hensley S, Pullmann MD, Benjamin PH, Lyon AR, et al. The role of the outer setting in implementation: associations between state demographic, fiscal, and policy factors and use of evidence-based treatments in mental healthcare. Implement Sci. 2019 Nov 13;14(1):96.

34. Rabin BA, Brownson RC, Haire-Joshu D, Kreuter MW, Weaver NL. A glossary for dissemination and implementation research in health. J Public Health Manag Pract JPHMP. 2008;14(2):117-23.

\section{Supplementary Files}

This is a list of supplementary files associated with this preprint. Click to download.

- Appendix1FINALdocx.docx 